\title{
Efek Diskritisasi pada Modifikasi Hypocycloid Menjadi CSCPP (Curve Stitching Connected Pseudo Polygon)
}

\author{
Hanna Arini Parhusip ${ }^{1^{*}}$ \\ ${ }_{1}$ Program Studi Matematika, Fakultas Sains dan Matematika, Universitas Kristen Satya Wacana \\ Jl. Diponegoro No. 52-60, Kota Salatiga 50711, Jawa Tengah, Indonesia \\ *Penulis Korespondensi. Email: hanna.parhusip@uksw.edu
}

\begin{abstract}
ABSTRAK
Tulisan ini membahas tentang pembuatan Curve Stitching berdasarkan efek diskritisasi kurva Hypocycloid yang dimodifikasi. Kurva yang dihasilkan dinamakan Connected Pseudo Polygon (CPP) karena berupa segibanyak yang berbentuk berdasarkan urutan cara menggambar serta diskritisasi titik yang digunakan. Yang dimaksud Curve Stitching disini adalah pembuatan ornamen dengan papan dan benang. Desain ini digunakan sebagai media bermain dalam kegiatan pelajaran atau kuliah matematika. Selain dengan benang, CPP juga dibentuk dengan kawat dan sedotan agar Desain yang sama dapat dibentuk dengan beberapa material yang cocok untuk penyusunan CPP. СPP ini digunakan sebagai media untuk mengilustrasikan inovasi matematika atau ornamen matematika.
\end{abstract}

Kata Kunci:

Hypocycloid ; Segibanyak; Curve Stitching

ABSTRACT

This paper describes creating Curves Stitching based on the innovation of modified hypocycloid. The modified hypocycloid curve depends on the discretization used for drawing. The results are Connected Pseudo Polygons (CPP) meaning the patterns are kind of polygons. Each edge must be connected orderly. Curve stitching here means that making ornament using threads on a plain wood following CPP. This curve stitching can be used as learning media for mathematics. Not only using threads, but CPP can also be made by a wire or a straw or other relevant materials. These CPPs are used to be media for illustrating innovation in mathematics or mathematical ornaments.

Keywords:

Hypocycloid; Polygon; Curve Stitching

Format Sitasi:

H. A. Parhusip, "Efek Diskritisasi pada Modifikasi Hypocycloid Menjadi CSCPP (Curve Stitching Connected Pseudo Polygon)," Jambura J. Math., vol. 2, no. 2, pp.60-72, 2020.

\section{Pendahuluan}

Curve Stitching adalah kurva yang terbentuk karena pergerakan benang-benang dengan pola tertentu yang diperkenalkan pertama kali oleh Mary Everest Boole (1832 -

e-ISSN: 2656-1344 (C) 2020 H.A. Parhusip | Under the license CC B Y-NC 4.0

Diterima: 8 Januari 2020 |Disetujui: 22 Februari 2020 |Online: 01 Maret 2020 
1916) sebagai salah satu matematikawan wanita pertama di Inggris. Pada umumnya Curve Stitching diperkenalkan pada sekolah-sekolah untuk memperkenalkan matematika agar lebih menarik. Misalkan $y=m x+c$ fungsi linear, fungsi parabolik, dinyatakan dalam benang-benang dengan arah-arah tertentu sehingga menyusun pola kurva baru pada bidang. Ada berbagai hasil seni yang dihasilkan baik berupa hiasan saja maupun untuk kebutuhan rumah tangga seperti kursi. Akan tetapi kegiatan ini masih sebagai kegiatan yang rutin dengan penyusunan kurva dari pola-pola klasik (garis dan atau kurva parabola). Untuk itu diperlukan inovasi yang lebih banyak terlebih dengan pengetahuan kurva-kurva parametrik yang ada.

Beberapa literatur menjelaskan tentang pembuatan kurva dan permukaan dimana Masalah dalam pembuatan kurva 2 dimensi dan permukaan 3 dimensi dapat dinyatakan secara parametrik ataupun implisit [1]. Misalkan pembuatan permukaan dikaitkan dengan Computer Aided Design (CAD) dimana pembuatan dilakukan dalam permukaan parametrik bentuk bebas seperti Bézier, B-spline dan fungsi-fungsi NURBS [2] yang bermanfaat dalam pembuatan gear. Demikian pula pembuatan kurva dapat dilakukan sebagai limit dari barisan kurva segibanyak dengan proses iterasi dalam kurva-kurva fractal [3] . Pendekatan kurva dan permukaan dan komputasi secara topologi dijelaskan dari konsep hingga hasil dimana efisiensi praktis diperhatikan [4]. Sedangkan pembuatan Curve Stitching pada tulisan ini dilakukan untuk membuat desain ornamen matematika. Pembuatan desain ornamen dengan matematika sudah berkembang pada beberapa negara. Selain untuk keperluan eksplorasi bagi dunia pendidikan, desain-desain yang dibuat juga banyak berpengaruh terhadap berbagai arsitektur modern.

Beberapa desain arsitektur pada bangunan modern banyak dijumpai yang menggunakan inovasi kurva dan permukaan [5]. Akan tetapi realisasi dengan industri yang terjadi masih pada negara maju seperti negara-negara di Eropa. Sedangkan pada negara berkembang seperti Indonesia, matematika belum dimanfaatkan secara langsung pada berbagai bidang dengan industri sekitar. Untuk itu pada bagian ini akan dibahas bagaimana matematika dapat terkait dengan industri sekitar. Karena jenis industri yang ada adalah industri rumah tangga, maka perlu penjelasan yang rinci untuk rancangan desain yang akan dibuat. Pada bagian ini ditunjukan beberapa rancangan desain dengan ukuran yang dikehendaki sehingga dapat diterjemahkan langsung pada tukang atau teknisi pada industri kecil tersebut. Industri kecil yang dimaksud misalnya tukang las. Jika material yang digunakan adalah kawat maka tukang las harus memahami desain dan panjang kawat dengan ukuran yang dikehendaki.

Pada tulisan ini, akan ditunjukkan bagaimana desain Curve Stitching dihasilkan dari persamaan hypocycloid yang dimodifikasi. Demikian pula barisan Fibonacci dapat digunakan untuk dapat menghasilkan kurva yang menarik yaitu kurva yang sudah ada digandakan sesuai urutan baris Fibonacci (Penyusunan desain sangat tergantung pada cara menggambar dimana program yang digunakan adalah MATLAB. Banyaknya titik yang digunakan mempengaruhi desain yang diperoleh selain dari parameter yang dipilih. Artinya untuk suatu kurva parametrik dapat diperoleh berbagai macam desain yang berbeda karena banyaknya titik yang digunakan berbeda sekalipun parameternya sama. Hal ini sebagai efek diskritisasi yang akan dibahas pada bagian selanjutnya. 


\section{H.A. Parhusip}

\section{Metode}

Pengenalan matematika sebagai bagian dari art liberal telah dilakukan oleh para matematikawan untuk dapat menjadikan pembuat kreator yang percaya pada art dan kreasinya bahkan hanya dengan mengeksplorasi kalkulus [6]. Oleh karena itu, pada bagian ini penulis melakukan eksplorasi hypocycloid yang diperoleh dari kalkulus untuk menjadi bentuk geometris yang bermacam-macam berdasarkan banyaknya titik dalam menggambar.

\subsection{Kurva Hypocycloid dan Modifikasinya}

Kurva hypocycloid adalah kurva pada bidang sebagai hasil posisi lingkaran dengan jarijari lingkaran dengan jari-jari $a$ mengelilingi lingkaran yang lebih besar dengan jari-jari $b$, dimana kurva ini mempunyai persamaan parametrik, sebagaimana ditunjukkan pada Persamaan (1),

$$
\left.\begin{array}{l}
\text { (a) } x=(b-a) \cos \theta+a \cos \left(\frac{b-a}{a} \theta\right) \\
\text { (b) } y=(b-a) \sin \theta-b \sin \left(\frac{b-a}{a} \theta\right)
\end{array}\right\}
$$

Persamaan ini adalah persamaan klasik hypocycloid yang sudah ada pada literatur [7]. Salah satu kurva yang juga dianggap menyerupai adalah epycycloid [8] yang telah dilakukan inovasi sehingga diperoleh berbagai bentuk yang dapat memuat hypocycloid. Adapun Persamaan (1) dimodifikasi yang mengabaikan hubungan nilai $a$ dan $b$ sebagai nilai jari-jari 2 lingkaran dimana $b>a>0$. Hal ini dimaksudkan agar diperoleh inovasi kurva bidang datar dengan persamaan ini. Persamaan inovasi kemudian digunakan untuk membentuk pola-pola Connected Pseudo Polygon (CPP) yaitu segi banyak (polygon) yang terbuat karena urutan dan banyaknya titik (vertex) untuk menggambar diperhatikan. Penggunaan istilah Pseudo polygon belum ada pada literatur kecuali pseudo triangle (pseudo triangulation) [9].

Perlu diperhatikan bahwa karena gambar dengan komputer, maka kita perlu titik-titik diskrit yang menyatakan pasangan $(x, y)$ dari setiap sudut yang diberikan. Lain halnya dengan segi banyak pada dimensi 2 yang pada umumnya tidak tergantung pada urutan menggambar. Misalkan, kita menggambar segitiga sama sisi tidak perlu harus urut titik vertex untuk memulai menggambar. Adapun pada CPP ini kita perlu memperhatikan urutan.

Untuk menjadikan suatu CPP dengan menggunakan materi 1 dimensi seperti benang, sedotan, kawat maka peletakan garis persilangan juga perlu diperhatikan agar terjadi keseragaman bentuk. Jika terjadi persilangan maka garis yang menyilang diletakkan di atas garis sebelumnya. Agar pembuatan dapat dilakukan dengan berbagai ukuran maka perlu dilakukan program komputasi panjang untuk tiap sisi CPP dan koordinat masing-masing titik antar sisi. Untuk itu pada subbab berikut dibuat cara perhitungan panjang sisi-sisi CPP.

\subsection{Penyusunan Curve Stitching CPP}

Modifikasi pada persamaan hypocycloid diberikan pada Persamaan (2), 


$$
\left.\begin{array}{l}
\text { (a) } x=(a+b) \cos \theta+b \cos \left(\frac{a+b}{b} \theta\right) \\
\text { (b) } y=(a+b) \sin \theta+b \sin \left(\frac{a+b}{b} \theta\right)
\end{array}\right\}
$$

dimana $a$ dan $b$ parameter bilangan real [10]. Sejauh ini masih dibatasi keduanya lebih besar 0 . Untuk menghitung panjang kurva parametrik $(S)$ secara analitik dengan kalkulus, diketahui

$$
S=\int_{\alpha}^{\beta} \sqrt{\left(\frac{d x}{d \theta}\right)^{2}+\left(\frac{d y}{d \theta}\right)^{2}} d \theta, \quad \alpha \leq \theta \leq \beta .
$$

Formulasi ini telah digunakan untuk menghitung keliling lingkaran, asteroid, atau kurva pada bidang datar yang ditulis dalam parametrik secara analitik. Lain halnya dexngan kurva-kurva yang dihasilkan oleh Persamaan (1) atau Persamaan (2) dimana kurva yang dihasilkan ditentukan oleh banyaknya titik yang digunakan untuk menggambar (karena dengan komputer). Salah satu kurva dihasilkan dengan beberapa variasi parameter dan banyaknya titik ditunjukkan pada Gambar 1.

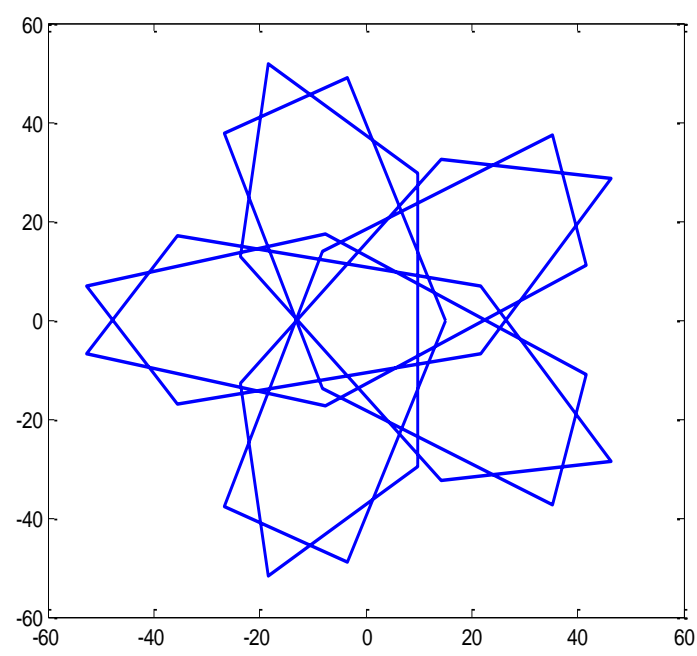

Gambar 1. Persamaan (1.b) dengan $a=15, b=\frac{p}{q} ; 0 \leq \theta \leq 0.56 \pi p, p=600$, $q=-30, n=30$ (banyaknya titik diskrit)

Dengan adanya berbagai kurva dari 1 persamaan yang sama, jelas bahwa formulasi analitik untuk menghitung panjang kurva Persamaan (2) tidak dapat digunakan. Oleh karena itu formulasi Phytagoras yang dapat digunakan dimana koordinat tiap sisi perlu diketahui secara otomatis sehingga panjang seluruh CPP hanya dengan menambahkan panjang tiap sisi.

\subsection{Pythagoras Numerik untuk Panjang Sisi}

Pada bagian ini kita akan menggambar kurva dengan cara mendiskritisasi nilai sudut dari suatu subinterval pertama dan dilanjutkan dengan subinterval ke-2. Kurva yang terjadi ditunjukkan pada Gambar 2. Program MATLAB juga ditunjukkan untuk dapat 


\section{H.A. Parhusip}

menjadi contoh cara menggambar bagi pembaca. Misalkan pada Gambar 2 adalah kurva dengan versi titik saja $\left(^{*}\right)$.

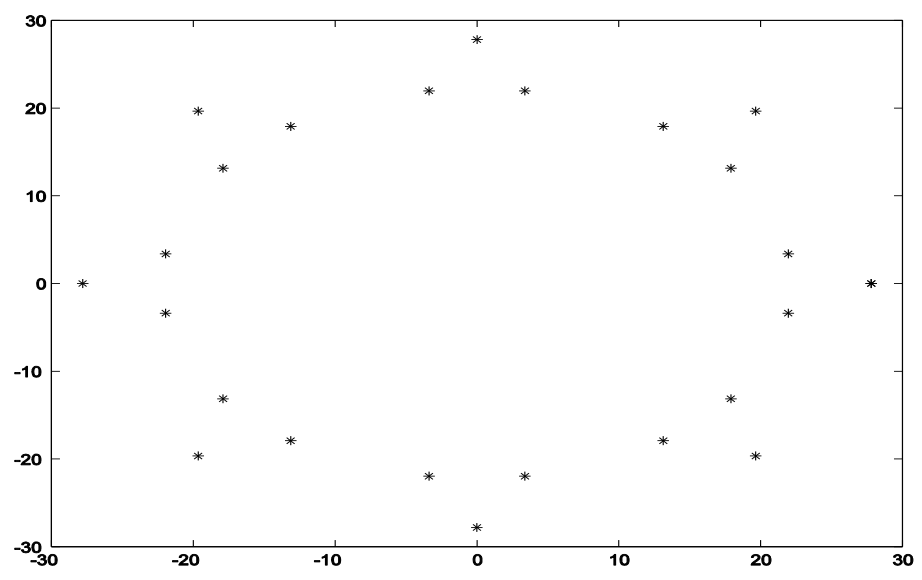

Gambar 2. Titik-titik penyusun Curve Stitching CPP Persamaan (1.b) $a=20, p=780$, $q=-200$, dan $b=3.9, n=25$ (banyaknya titik yang digunakan untuk menggambar)

Selanjutnya desain yang sama digambar dengan versi garis yang ditunjukkan pada Gambar 3.

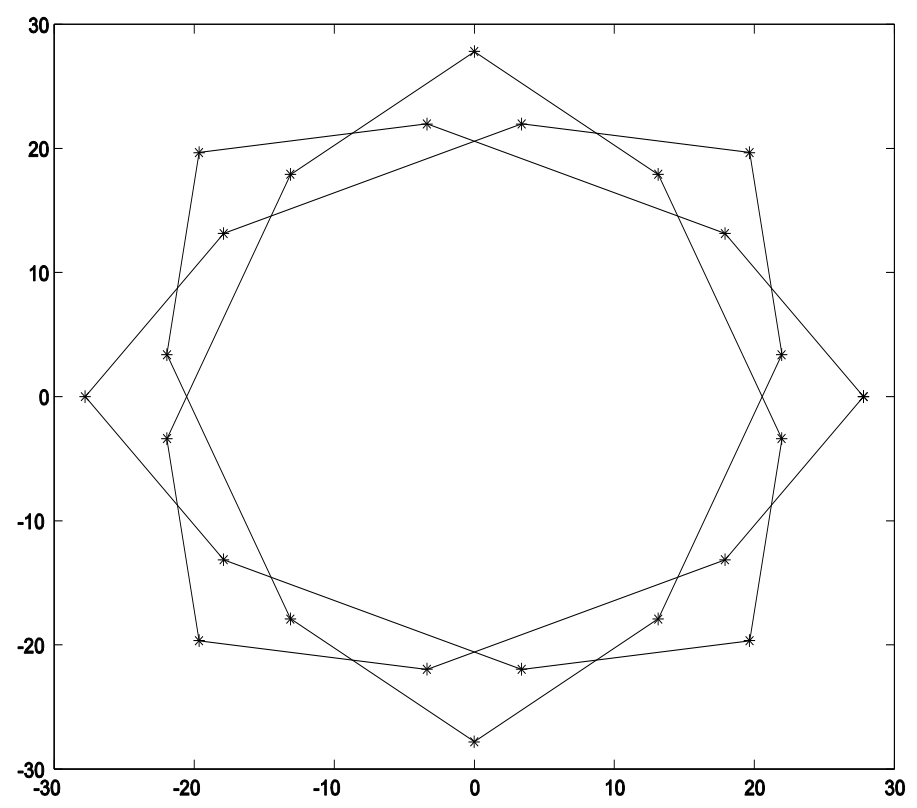

Gambar 3. Kurva modifikasi hypocycloid dari Persamaan (2.a) dengan $a=20$, $p=780, q=-200$, dan $b=3.9, n=25$ (banyaknya titik yang digunakan untuk menggambar) dengan titik $\left(^{*}\right)$ dan garis

Padahal kita menghendaki panjang kurva yang dibentuk antar 2 titik berturutan yang kemudian ditambahkan. Jadi secara sederhana kita perlu mengetahui jarak antar 2 titik sehingga kita dapat menggunakan hukum Phytagoras. Hanya saja, tentu kita 
harus tahu apakah garis yang dibentuk antar 2 titik yang berturutan atau tidak. Untuk itu perlu indeks dan koordinat yang jelas terlihat.

Gambar 4 menghubungkan titik ke-1, ke-2 dan ke-3 yang berturut-turut disimbolkan pada titik A, B dan C. Dari daftar jarak antar 2 titik yang diperoleh maka ada 2 macam potongan 1 dimensi antar 2 titik yang berturutan. Ingat masing-masing belum punya satuan sebagaimana diilustrasikan pada Gambar 4.

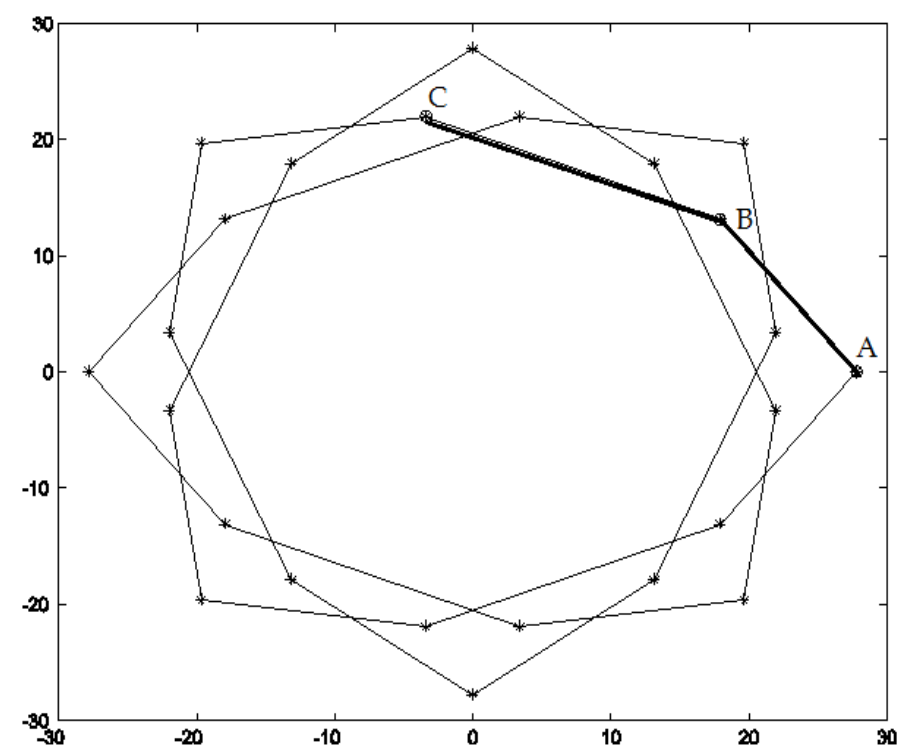

Gambar 4. Persamaan (2) dengan $a=20, p=780, q=-200$, dan $b=3.9, n=25$ (banyaknya titik diskrit untuk menggambar) dengan titik $\left(^{*}\right)$ dan garis dimana titik pertama, kedua dan ketiga berturut-turut pada $\mathrm{a}, \mathrm{b}$ dan $\mathrm{c}$

Masalah selanjutnya bagaimana menginstruksi tukang agar dapat membuat tepat sesuai ukuran yang kita berikan. Ingat sekalipun desain diberikan tidak serta merta dipahami oleh industri kecil. Oleh karena itu koordinat dan ukuran tiap pasang titik perlu jelas, sehingga perlu diberikan pelabelan pada setiap titik. Demikian dalam pembuatan CSCPP harus memperhatikan pelabelan sehingga pembuatan massal CSCPP tetap mempunyai pola yang sama. Dari batang dengan nomor titik dimulai dari 1 hingga ke 9 maka untuk menyusun batang kawat dari ke-9 dengan ke-10 akan bersilangan dengan batang dari titik ke-1 dan ke-2. Oleh karena itu, batang dengan koordinat ke- 9 dan ke-10 harus berada di atas batang pertama (koordinat ke-1 dan koordinat ke-2). Adapun potongan kawat dengan indeks ke 10 dan ke-11 belum bersilangan dengan batang yang ada. Karena pada penyusunan tahap ini, batang tersebut belum dipasang. Adapun batang dengan label ke-11 dan ke-12 harus di atas dan bersilangan dengan batang dengan label ke-2 dan ke-3. Demikian seterusnya.

\subsection{Menetapkan Ukuran Praktis dalam Dimensi}

Jika potongan sudah diberikan, masalah yang timbul selanjutnya adalah menata batang-batang tadi dalam bentuk yang dikehendaki dengan tepat. Untuk itu maka perlu pola penskalaan yang harus dipenuhi. Berdasarkan gambar yang dihasilkan maka diperlukan penskalaan sebagai berikut, 


\section{H.A. Parhusip}

a) Panjang sisi perlu dihitung, hal ini didefinisikan sebagai,

$$
\begin{aligned}
& \Delta x_{i}=x_{i+1}-x_{i} \\
& \Delta y_{i}=y_{i+1}-y_{i}
\end{aligned}
$$

untuk $i=1, \ldots, n-1$. Selanjutnya hukum Phytagoras dapat diterapkan.

b) Untuk sumbu horizontal dan vertikal perlu diskala sebagai berikut,

$$
\begin{aligned}
& \bar{x}=\max (x)+|\min (x)| \\
& \bar{y}=\max (y)+|\min (y)|
\end{aligned}
$$

Selanjutnya dicari referensi untuk panjang sumbu yaitu,

$$
D=\max \{\bar{x}, \bar{y}\}
$$

Selanjutnya ditetapkan referensi panjang sisi-sisi sebagai batas luar objek 2 dimensi yang akan dibuat, misalkan disebut sebagai $L_{\text {ref }}$. Jadi tiap sisi harus dihitung panjangnya dan kemudian diskalakan dalam bentuk berdimensi dimana setiap sisi dihitung,

$$
l_{i}=\sqrt{\Delta x_{i}^{2}+\Delta y_{i}^{2}}, i=1, \ldots, n
$$

Pendekatan ini juga telah diusulkan oleh seorang peneliti bahwa algoritma untuk mengestimasi parameter dalam kurva dan permukaan parametrik dengan cara meminimalkan jumlah kuadrat tersebut dari jarak terpendek antara 2 kurva/permukaan dengan titik-titik yang diberikan [11].

Selanjutnya, bagaimana tukang mengikuti pola gambar setelah materi diperoleh? Perhatikan bahwa kemiringan/sudut harus tepat agar masing-masing potongan terhubung dengan benar. Oleh karena itu perlu ada komunikasi lebih lanjut dengan pelaku industri. Diantaranya adalah membuatkan sketsa desain sesuai ukuran yang dikehendaki. Jika koordinat sudah ada, maka urutan pemasangan penting untuk diperhatikan. Urutan yang berbeda akan memberikan tumpang tindih pada kawat yang berbeda. Jadi indeks pada tiap titik diperlukan agar tukang dapat mempunyai pola tumpang tindih kawat yang sama. Jadi program perlu dimodifikasi untuk menampilkan indeks. Bagian program yang memuat indeks sesuai koordinat ditunjukkan pada bagian selanjutnya.

\section{Hasil dan Pembahasan}

Sebagaimana disebutkan pada metode penelitian, terdapat beberapa macam CPP yang dapat dibuat dengan memvariasi banyaknya titik untuk menggambar pada Persamaan (2). Oleh karena itu di bawah ini diberikan beberapa CPP yang diperoleh yang digunakan untuk pembuatan CSCPP ataupun ornamen matematika. Dibandingkan dengan visualisasi kurva oleh literatur yang lain, seperti kurva dari persamaan Lorenz 
yang memperhatikan kelengkungan kurva [12], maka desain yang diperoleh ini sangat ditentukan oleh diskritisasi yang digunakan.

\subsection{Desain-Desain yang Dipilih dalam Curve Stitching}

Keunikan Curve Stitching pada umumnya ditentukan oleh pola dan banyaknya dan jenis material yang digunakan. Oleh karena itu, beberapa pola yang diperoleh perlu dipilih dan hasil ditunjukkan pada Gambar 5-7.

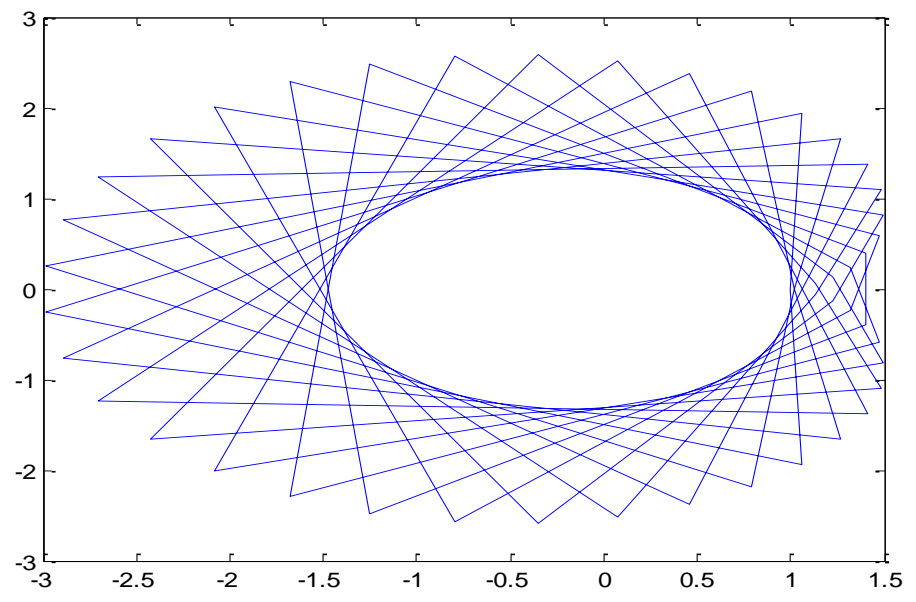

Gambar 5. Persamaan (2) dengan $a=1, b=\frac{p}{q}, p=24$ dan $q=12,0 \leq \theta \leq 2 p \pi$.

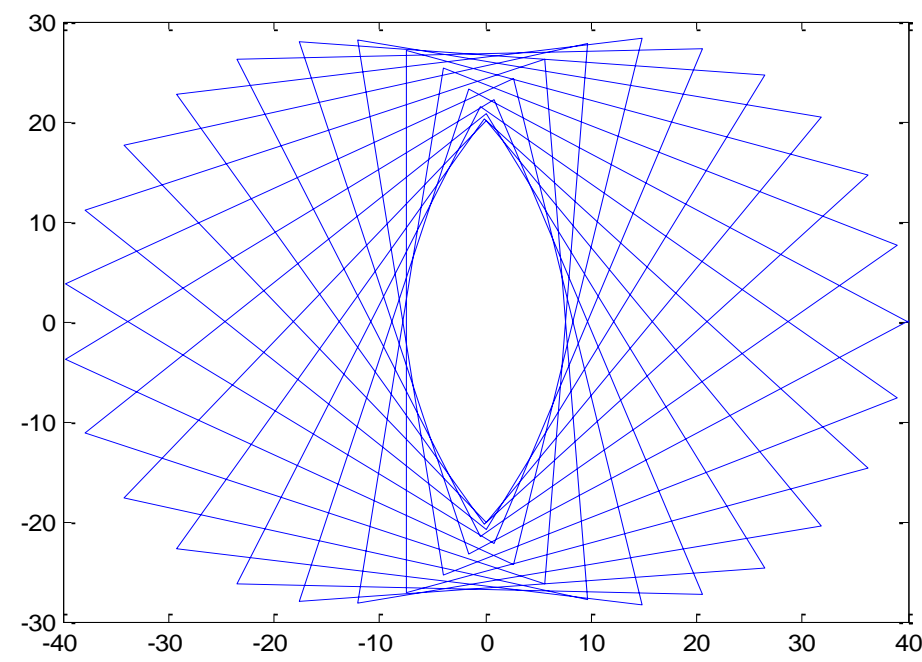

Gambar 6. Persamaan (2) dengan $a=20, p=750, q=-75, b=10$, dan $n=50$

Untuk dapat membuat pola Gambar 5-7, maka setiap titik perlu diberi label secara otomatis sebagaimana dijelaskan pada bagian metode. Selain pemberian label, perlu ditetapkan bahwa jika terjadi penumpukan penyusunan maka penumpukan dilakukan diatas kawat yang sudah ada. 


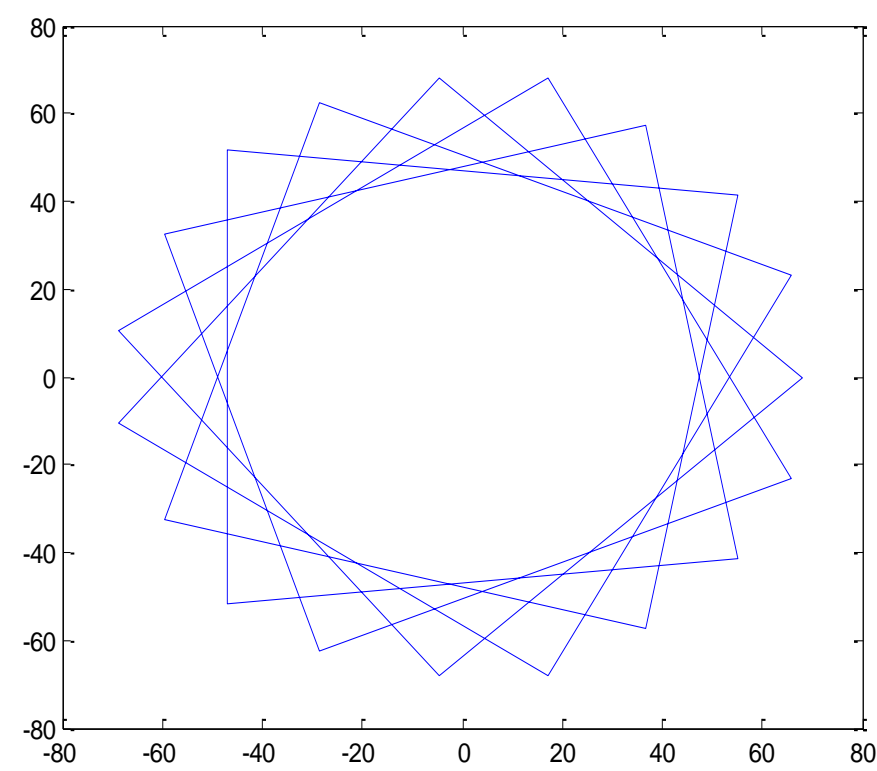

Gambar 7. Persamaan (1.b) dimana $a=70, p=180, q=170$, dan $b=-1.05, n=20$ (banyaknya titik yang digunakan untuk menggambar)

\subsection{Hasil-Hasil CPP dan Pengembangan}

Beberapa desain di atas kemudian dibuat dengan benang, kawat dan sedotan. CSCPP dengan benang dan sedotan dikerjakan oleh mahasiswa sebagai materi kuliah matematika industri sehingga hasil desain dapat digunakan sebagai prototipe untuk berbagai keperluan. Adapun desain dengan kawat harus dikerjakan dengan industri rumah tangga. Gambar 8 dan Gambar 9 adalah hasil CSCPP dengan desain berturutturut dari Gambar 5 dan Gambar 7.

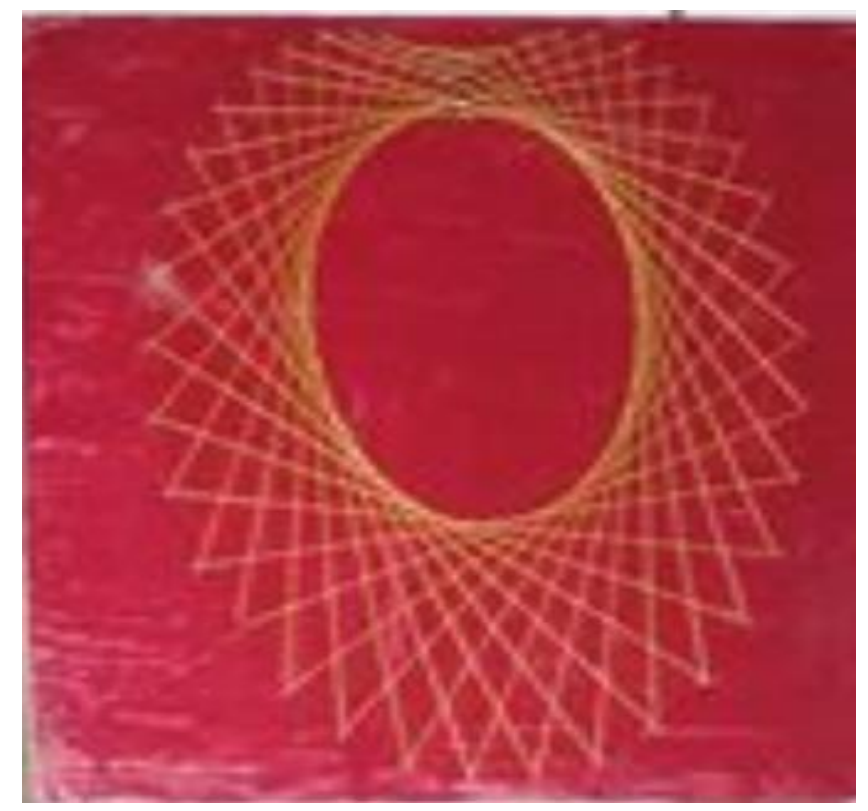

Gambar 8. Hasil CSCPP dengan desain dari Gambar 6 


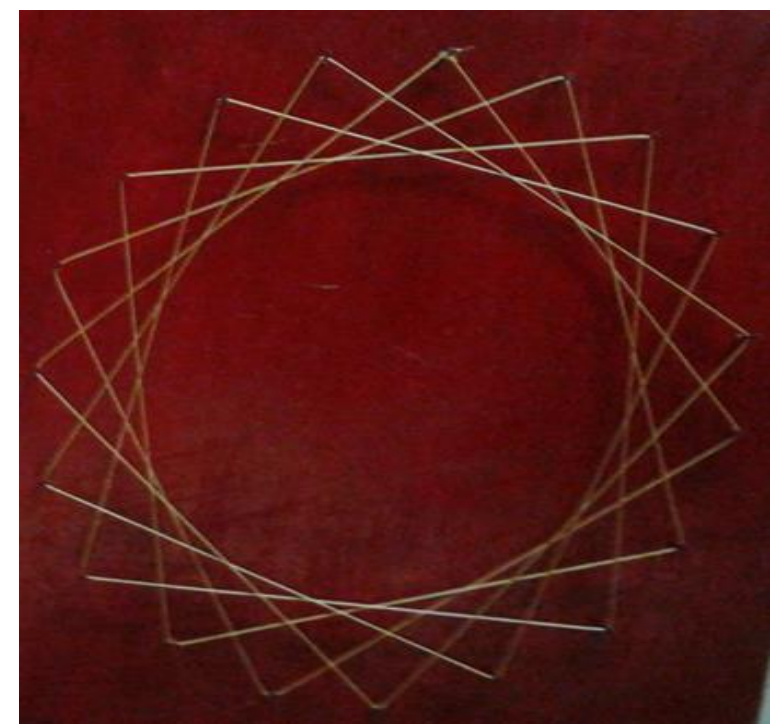

Gambar 9. Hasil CSCPP dengan desain dari Gambar 7

Pola pada Gambar 7 juga menjadi kegiatan pola Curve Stitching dengan aturan yang berbeda pada kegiatan Science \& Engineering Festival yang dibawakan di Washington DC pada Apri 16-17, 2016. Jadi pola-pola yang terbuat dapat menjadi media yang memperkenalkan matematika dengan cara yang kreatif dan inovatif. Desain yang serupa pada museum matematika MoMath di Amerika juga diperoleh namun tidak dibuat dari kurva modifikasi hypocycloid. Hal ini menunjukkan bahwa hasil pada penelitian ini original dan masih dimungkinkan dibentuknya berbagai CPP yang variative, yang dapat digunakan untuk media bermain siswa ataupun mahasiswa dalam memperkenalkan inovasi dan kreativitas matematika.

\subsection{CPP pada Ornamen Matematika}

Desain yang ditunjukkan pada Gambar 4-7 dapat digunakan sebagai acuan untuk membuat ornamen matematika dari bahan sedotan atau kawat. Pada tulisan ini ditunjukkan hasil ornamen dengan desain CPP dari Gambar 4 dengan menggunakan sedotan dan kawat.

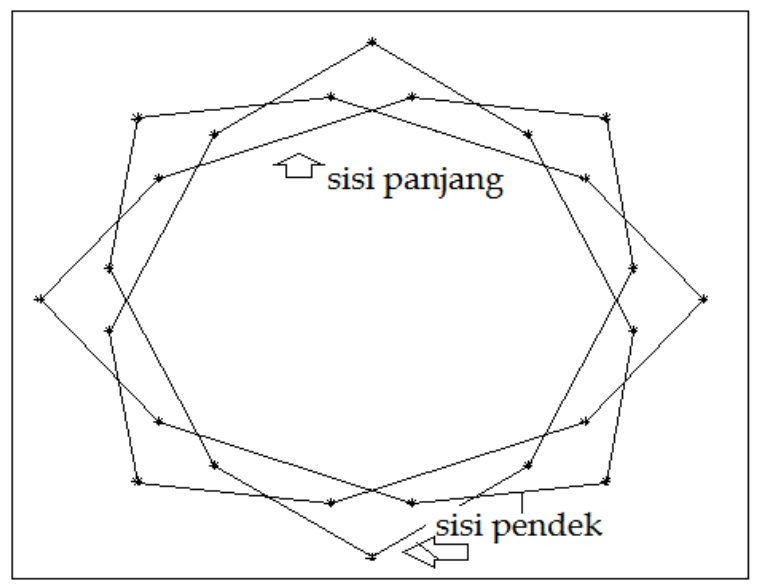

Lref $=\max ($ sisi luar $)$

Gambar 10. Penamaan $L_{r e f}$, sisi pendek dan sisi panjang pada Gambar 4 


\section{H.A. Parhusip}

Sedotan dan kawat dipilih karena termasuk material yang murah dan paling aman bagi siswa. Meksi demikian, desain tersebut harus dengan ukuran yang cukup masuk akal. Berbagai ukuran yang dikehendaki dapat dibuat dengan mengikuti pola penskalaan pada bagian subbab 2.4. Referensi yang digunakan adalah panjang sisi terluar yang melingkupi gambar/desain, sehingga kita dapat menyusun beberapa ukuran CPP Gambar 4 yang terdiri dari 8 sisi panjang dan 16 sisi pendek yang digambarkan pada Gambar 10. Ukuran yang berkaitan dengan sisi panjang, sisi pendek dan sudut penyusun tiap 2 sisi berturutan dinyatakan pada Tabel 1 .

Tabel 1. Data ukuran panjang sisi polygon tiap panjang referensi yang dipilih $\left(L_{r e f}\right)$

\begin{tabular}{|c|c|c|c|c|}
\hline Keterangan & $L_{r e f}=10 \mathrm{~cm}$ & $2^{*} L_{r e f}$ & $3 L_{r e f}$ & $5 L_{r e f}$ \\
\hline Ukuran sisi pendek & 2,9570 & 5,9139 & 8,8709 & 14,7848 \\
\hline Ukuran sisi panjang & 4,1440 & 8,2880 & 12,4320 & 20,7200 \\
\hline $\begin{array}{l}\text { Sudut sisi pendek dan sisi panjang } \\
\text { (derajat) }\end{array}$ & 149,4848 & 149,4848 & 149,4848 & 149,4848 \\
\hline $\begin{array}{l}\text { Sudut sisi pendek dan sisi pendek } \\
\text { (derajat) }\end{array}$ & 106,0305 & 106,0305 & 106,0305 & 106,0305 \\
\hline
\end{tabular}

Dengan bidang yang melingkupi CPP adalah $30 \mathrm{~cm} \times 30 \mathrm{~cm}$, dibuat ornamen matematika dengan sedotan sebagaimana ditunjukkan pada Gambar 11.

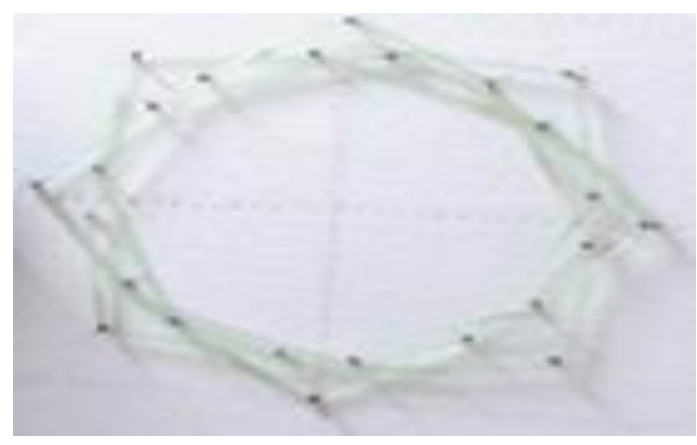

Gambar 11. Pembuatan ornamen matematika CPP dengan sedotan menurut pola Gambar 4

Selanjutnya, dengan menggunakan referensi dan ukuran yang sama, dibuat ornamen matematika dengan bahan kawat sebagaimana ditunjukkan pada Gambar 12.

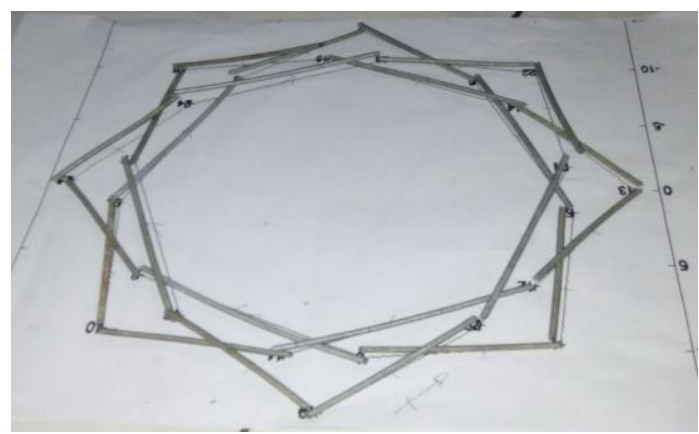

Gambar 12. Pembuatan ornamen matematika CPP dengan kawat menurut pola Gambar 4 
Sejauh ini karya-karya Curve Stitching tidak banyak dihasilkan sebagai karya tertulis dalam jurnal yang bereputasi karena dasar keilmuan yang digunakan sangat sederhana tetapi dengan melakukan variasi dan inovasi kurva-kurva sederhana dengan cara berbeda. Oleh karena itu tidak banyak pustaka yang dapat dirujuk pada tulisan ini sekalipun terdapat juga penulis yang membahas tentang kurva dengan art yang terkait [13]. Demikian pula pemanfaatan kurva hypocycloid umumnya muncul pada aplikasi mekanika seperti pada gear [14][8][15] untuk mempelajari gerak kinematik antar 2 gerak linear hypocycloid. Hal inilah yang menjadi novelti dalam tulisan ini dimana hypocycloid dapat dimanfaatkan dalam pembuatan Curve Stitching sebagai media kreatif pada matematika.

\section{Kesimpulan}

Pada tulisan ini telah dibahas penyusunan Curve Stitching dengan modifikasi persamaan hypocycloid yang mengabaikan makna geometris dari nilai parameter yang digunakan. Terdapat beberapa kurva dimana kurva dengan garis lurus dipilih sebagai golongan Connected Pseudo Polygon (CPP). Pembentukan yang diperoleh berdasarkan urutan pemasangan sehingga setiap titik penghubung 2 sisi berturutan diberi label angka urutan pemasangan. CPP dibuat sebagai Curve Stitching Connected Pseudo Polygon (CSCPP) dari benang dan ornamen dari sedotan dan kawat.

\section{Ucapan Terimakasih}

Tulisan ini merupakan luaran dari penelitian yang didanai oleh dana penelitian internal UKSW dengan judul BMOV tahun anggaran 2018/2019.

\section{Referensi}

[1] G. Taubin, "Estimation of planar curves, surfaces, and nonplanar space curves defined by implicit equations with applications to edge and range image segmentation," IEEE Trans. Pattern Anal. Mach. Intell., vol. 13, no. 11, pp. 1115$1138,1991$.

[2] A. Iglesias et al., "Cuckoo Search Algorithm with Lévy Flights for GlobalSupport Parametric Surface Approximation in Reverse Engineering," Symmetry (Basel)., vol. 10, no. 3, p. 58, Mar. 2018.

[3] G. Irving and H. Segerman, “Developing fractal curves," J. Math. Arts, vol. 7, no. 3-4, pp. 103-121, Dec. 2013.

[4] J. D. Boissonnat and M. Teillaud, Effective Computational Geometry for Curves and Surfaces. Springer Berlin Heidelberg, 2006..

[5] A. Biran, "Parametric Curves," in Geometry for Naval Architects, Technion: Elsevier, 2019, pp. 197-222.

[6] C. von Renesse and V. Ecke, "Discovering The Art of Mathematics: Using String Art to Investigate Calculus," PRIMUS, vol. 26, no. 4, pp. 283-296, Apr. 2016.

[7] M. Henle and B. Hopkins, Eds., Martin Gardner in the Twenty-First Century. Washington: The Mathematical Association of America, 2012.

[8] D. M. Freeman, "Epicycloid curves and continued fractions," J. Math. Arts, vol. 


\section{H.A. Parhusip}

11, no. 2, pp. 100-113, Apr. 2017.

[9] O. Aichholzer, F. Aurenhammer, C. Huemer, and H. Krasser, "Transforming spanning trees and pseudo-triangulations," Inf. Process. Lett., vol. 97, no. 1, pp. 19-22, Jan. 2006.

[10] H. A. Parhusip, "Arts revealed in calculus and its extension," Int. J. Stat. Math., vol. 1, no. 3, pp. 016-023, 2014.

[11] C. Li and G. P. Peterson, "Parametric Study of Pool Boiling on Horizontal Highly Conductive Microporous Coated Surfaces," J. Heat Transfer, vol. 129, no. 11, pp. 1465-1475, Nov. 2007.

[12] H. M. Osinga and B. Krauskopf, "Visualizing curvature on the Lorenz manifold," J. Math. Arts, vol. 1, no. 2, pp. 113-123, Jun. 2007.

[13] J. Nicol, On the Curve The Life and Art of Sybil Andrews Janet Nicol. Canada: Caitlin Press Inc., 2019.

[14] S. Wang, J. Zhu, X. Wang, Q. Li, and H. Zhu, "Kinematics Modeling and Simulation of a Bionic Fish Tail System Based on Linear Hypocycloid," Appl. Bionics Biomech., vol. 2015, pp. 1-8, 2015.

[15] M. Florez, V. Carbonell, and E. Martinez, “Design of Cycloids, Hypocycloids and Epicycloids Curves with Dynamic Geometry Software," in Engineering applications, Edulearn11 Proceedings, 2011, pp. 1011-1016. 